\title{
Ergonomia: estudo de caso em biblioteca universitária
}

\author{
Daniela Capri \\ Complexo de Ensino Superior de Santa Catarina Florianópolis - CESUSC, Brasil \\ Eliana Maria dos Santos Bahia \\ Adilson Luiz Pinto \\ Universidade Federal de Santa Catarina - UFSC, Brasil
}

\section{CASE REPORT}

\begin{abstract}
Resumo
Buscou-se nesta pesquisa analisar a ergonomia real de uma Biblioteca Universitária de Florianópolis/SC e confrontá-la com a ergonomia percebida pelo usuário, para realização de um diagnóstico ergonômico. Os sujeitos pesquisados preencheram uma amostra de quinze pessoas, entre alunos da Biblioteca e funcionários do local. Com o intuito de atender este pontos, foram estabelecidos dois objetivos específicos: descrever os aspectos físico-ambientais da Biblioteca, vinculados à Ergonomia real e verificar a percepção dos usuários em relação à Biblioteca. Aspectos sobre Ergonomia e sua aplicação vinculados à Biblioteca Universitária. Analisaram-se as condições de iluminação, ruído e temperatura. Amparado por uma bibliografia, o presente estudo apresenta mercado de trabalho para o profissional de Arquivologia e Biblioteconomia.
\end{abstract}

Palavras-chave

Ergonomia; Ergonomia ambiental ; Biblioteca universitária

\section{Ergonomics: case study in a university library}

\begin{abstract}
This final paper aimed to analyze the real ergonomics of a university library from Florianópolis and compare it with the ergonomics perceived by the user to perform an ergonomic diagnosis. In order to meet this goal two specific goals were established such as: describe the physical and environmental aspects of the library related to the real ergonomics and verify the actual perception of users about the library. As a theoretical approach, aspects of ergonomics and environmental ergonomics were contextualized and linked to the library and the university library. Referring to the methodology, the Ergonomical Assessment of the Built Environment was used as a reference. The study subjects comprised a sample of 15 , among students and library staff. In the results obtained, when related to the physical-environmental analysis of the library, it was found that there are some aspects that differ from the regulatory standards and that also fall short in relation to feedback from users. Aspects such as lighting and noise were cited as unsatisfactory, but the temperature factor was analyzed as satisfactory.
\end{abstract}

\section{Keywords}

Ergonomics; Environmental ergonomics ; University library 


\section{Introdução}

Para atender à demanda de seus usuários, as organizações precisam se ajustar às exigências e às mudanças que ocorrem a todo o momento. Na contemporaneidade, as ciências surgem para atender a sociedade e, dentro delas, está inserida a Ergonomia, que pode ser considerada uma ciência multidisciplinar.

Em foco na pesquisa, tem-se uma Biblioteca Universitária em Florianópolis/SC, há a preocupação com a satisfação do usuário, no sentido dos serviços disponibilizados e do encontro da informação requerida. Aspectos ambientais da Biblioteca, que envolvem iluminação, temperatura, ruídos e sinalização geralmente pouco questionados.

Ao desenvolver o tema Ergonomia, o estudo de caso na Biblioteca Universitária em Florianópolis/SC pretende realizar uma avaliação ergonômica do ambiente utilizado pelos usuários, averiguando-se a satisfação dos mesmos.

Trata-se de uma pesquisa qualitativa e utiliza Normas regulamentadoras de segurança e saúde no trabalho : NR17 - Ergonomia, publicada e adotada pelo MINISTÉRIO DO TRABALHO e EMPREGO.

O Posto de Trabalho da Biblioteca é o instrumento base para fazer uma análise do ambiente como um todo (salas de estudo, mobiliário, iluminação, temperatura, ruídos, disposição dos móveis, layout).

Para a unidade de informação (Arquivo e Biblioteca), trata-se de uma área de conhecimento na aplicação da percepção da Ergonomia quanto aos fatores ambientais.

\section{Procedimentos metodológicos}

A pesquisa realizada entre março a outubro de 2011, utilizou como método, a pesquisa qualitativa.

Aplicou-se um questionário constituído por questões abertas e fechadas, a todos os usuários (alunos e funcionários) da Biblioteca analisada, com o intuito de verificar o conhecimento que os alunos possuem em Ergonomia e a percepção dos colaboradores em relação à mesma. A pesquisa se dá com uma amostra não probabilística de 15 usuários da biblioteca e 6 funcionários. Para a realização da coleta de dados foi utilizado o método de avaliação ergonômica do ambiente que segundo Vasconcelos, Villarouco e Soares (2009, p. 9), "[...] o método é aplicado a partir de três etapas: análise física, análise da percepção de usuário e diagnóstico ergonômico", conforme exposto no quadro a seguir.

\begin{tabular}{|c|c|c|}
\hline Análise físico-ambiental & Análise da percepção & Diagnóstico ergonômico \\
\hline $\begin{array}{l}\text { Descrição da localização física, da } \\
\text { configuração ambiental e do layout } \\
\text { da Biblioteca através de plantas } \\
\text { arquitetônicas e observação do } \\
\text { ambiente. }\end{array}$ & $\begin{array}{l}\text { Análise dos questionários com } \\
\text { usuários para identificação de } \\
\text { imagem de Biblioteca. }\end{array}$ & $\begin{array}{l}\text { Evidenciar os aspectos que } \\
\text { conduzem à análise físico- } \\
\text { ambiental em relação à análise da } \\
\text { percepção do usuário. }\end{array}$ \\
\hline 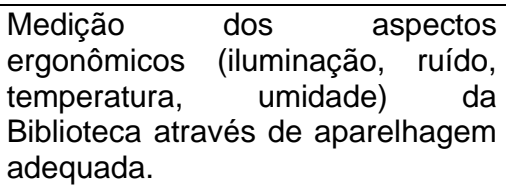 & $\begin{array}{l}\text { Análise dos questionários aplicados } \\
\text { para identificação da percepção da } \\
\text { ergonomia da Biblioteca analisada. }\end{array}$ & $\begin{array}{l}\text { Verificar se a medição dos } \\
\text { aspectos ergonômicos (iluminação, } \\
\text { ruído, temperatura, umidade) } \\
\text { condiz com os indicados nas } \\
\text { Normas de Ergonomia. }\end{array}$ \\
\hline $\begin{array}{l}\text { Aplicação do questionário com os } \\
\text { funcionários para coletar dados } \\
\text { sobre conforto ambiental. }\end{array}$ & & \\
\hline
\end{tabular}

Quadro 1 - Metodologia

Fonte: CAPRI. Daniela. Ergonomia: um estudo de caso realizado em uma biblioteca universitária de Florianópolis. 2011. 80 f. Trabalho de Conclusão de Curso. (Graduação em Biblioteconomia) - Universidade Federal de Santa Catarina, Florianópolis, 2011. (2011) 


\section{Posto de trabalho na biblioteca}

A Biblioteca Universitária está localizada na cidade de Florianópolis/SC, no bairro de Santo Antonio de Lisboa. Possui como público principal estudantes de três cursos de Ensino Superior (Administração, Direito, Psicologia); Técnico em Design de Interiores; Cursos de Pós-graduação; Ensino Fundamental e Médio, que funciona paralelamente à Faculdade. Além deste público, a Biblioteca também atende funcionários e professores de toda a Instituição; moradores dos Bairros de Sambaqui, Santo Antonio de Lisboa, Cacupé e Ratones, que podem utilizar a Biblioteca somente para consulta no local.

A equipe é composta por um bibliotecário e sete auxiliares de biblioteca, sendo divididos em três estudantes de Biblioteconomia, um auxiliar, formado em Psicologia e dois auxiliares de nível médio. O horário de funcionamento da Biblioteca é das 7h30min às 22h30min, de segunda à sexta-feira, e das 9h às 13h, aos sábados. Os serviços oferecidos aos usuários são: consulta on-line ao acervo; empréstimo domiciliar; reserva e renovação on-line; levantamento bibliográfico; comutação bibliográfica; catalogação na fonte; capacitação do usuário (programas de orientação para pesquisa, normalização de documentação e informação, de acordo com as normas da Associação Brasileira de Normas Técnicas (ABNT)); disponibiliza-se também um manual de normalização de trabalhos acadêmicos.

O acervo da Biblioteca dispõe de - livros, periódicos, teses, dissertações, monografias, CD-ROM's e DVDs. Além dos materiais físicos, disponibiliza links em seu site para bases de dados e periódicos com acesso aberto. Quanto ao layout da Biblioteca, cada tipo de material encontra-se em ambientes distintos:

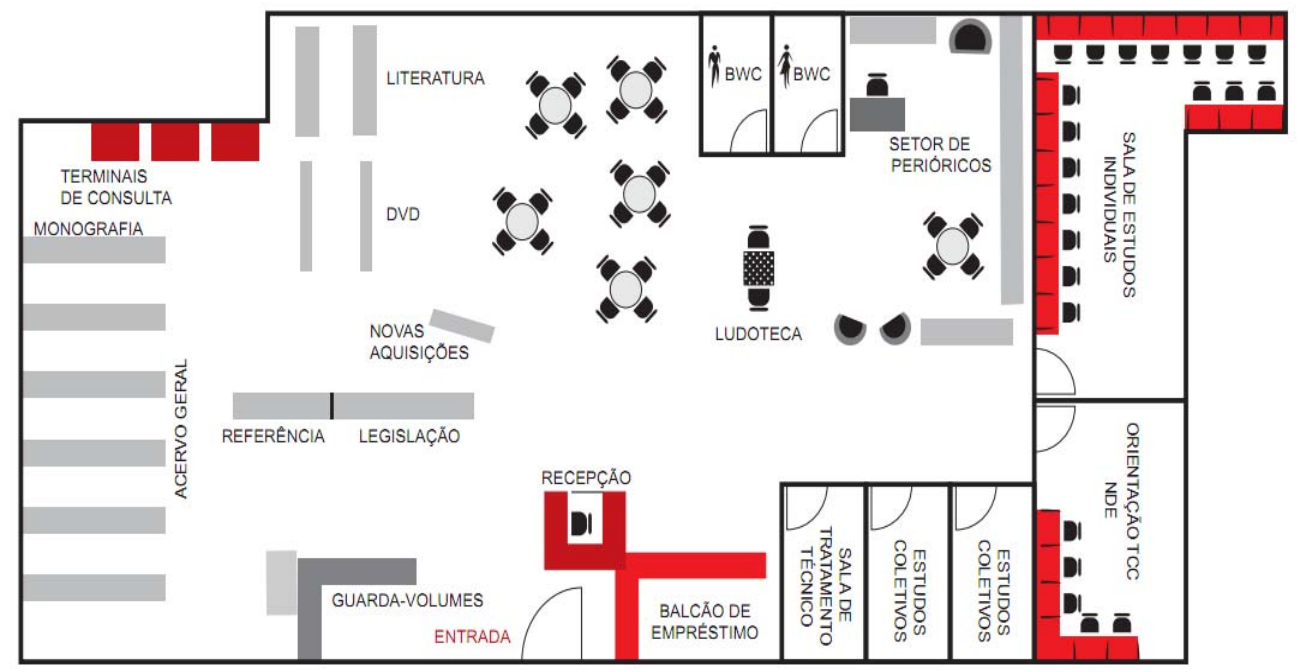

Figura 1 - Layout da biblioteca

\subsection{Configuração ambiental}

Assim, conforme figura 1, no hall de entrada, localiza-se o guarda-volumes e uma mesa para que os usuários retirem seus materiais. À direita da porta de entrada está localizado o balcão de empréstimo e uma divisória, junto à qual se localiza o setor de tratamento técnico. À frente do balcão de empréstimos, ficam as mesas de estudo. À esquerda das mesas, localiza-se o acervo, dividido em setor de referência, acervo geral, literatura e DVD's. À direita das mesas de estudo, está localizado o setor de periódicos e mesa para jogo de xadrez. As duas salas de estudos coletivos estão localizadas em frente ao setor de periódicos e a de estudos individuais, ao fundo da Biblioteca.

Em relação à disposição da Biblioteca dentro da arquitetura do prédio da Instituição, essa se encontra no segundo andar, com acesso por escadas ou elevador externo. De acordo com Lemos e Paixão (1999), a localização de uma 
biblioteca deve ser muito bem pensada, pois além de facilitar o acesso, o peso dessa unidade de informação é muito elevado. Devem ser levados em conta o "peso vivo"1 e o "peso morto"², portanto, as estruturas precisam ser bem planejadas e construídas.

Ao avaliar o ambiente físico interno da Biblioteca, verifica-se que as paredes e o teto são pintados de branco, o que dá sensação de claridade. Também para auxiliar na claridade, janelas ajudam a iluminação natural. A escolha da cor apresentada pode ser justificada no texto de Souto, Marx e Pedreira (1999); determinando que neste tipo de ambiente, a pintura deve ser em cor clara, que transmite sensação de tranquilidade, concentração e reflete melhor a luz. Não devem ser usadas cores escuras, nem nas paredes, nem no mobiliário, porque estas agitam e cansam os usuários. Apenas o piso e alguma decoração devem ser de cor escura. Porém, Azevedo, Santos e Oliveira (2000), observam que as cores devem ser dosadas, pois, se utilizadas cores frias demais, estas podem deixar o ambiente com aspecto depressivo. Neste aspecto, na Biblioteca analisada, as cores denominadas frias estão predominantemente presentes em todo o ambiente, pois, piso, paredes, mesas e teto são brancos. As cores em tons mais escuros se apresentam nos estofados das cadeiras e nas portas dos guarda-volumes, tornando o local monótono.

Em relação ao ambiente de uma biblioteca, Costa, Ziegler e Rollo (1999) abordam entre outros os pontos: Adaptar cabines de estudo individual; Criar áreas de silêncio com devido isolamento acústico; Uso de carpete e/ou pisos sintéticos para abafar o barulho dos passos; posicionamento das mesas/balcões de trabalho distantes das áreas de silêncio; Colocar cartazes convidando ao silêncio.

No entanto, a estrutura da Biblioteca analisada não comporta espaços específicos para a distribuição das estantes de acervo, do hall de entrada, do balcão de atendimento e das mesas de estudo, as únicas salas separadas são as de estudo coletivo, individuais e o setor de tratamento técnico (este último sem isolamento acústico).

No isolamento acústico, as janelas de toda a Biblioteca não são vedadas, o que aumenta o ruído em momentos de intervalo e almoço, pois a Biblioteca localiza-se sobre a praça de alimentação e corredores que são utilizados como áreas de lazer. O piso de toda a Biblioteca é de cerâmica e não abafa o barulho dos passos e do arrastar das cadeiras, fato que interfere na concentração dos usuários. Segundo Silvestre (1992, apud PEREIRA; SILVA; SALES 2011), os ruídos chegam a provocar uma redução de até $60 \%$ da produtividade, por dificultar a concentração, propiciando erros, desperdícios ou acidentes. Desta maneira, a solução está em utilizar as salas de estudos individuais que possuem isolamento acústico.

\subsection{Avaliação do ambiente no desempenho das atividades}

Para esta análise, foram selecionados para a amostra os funcionários da Biblioteca, pelo fato de passarem mais tempo no local. As perguntas desta etapa consistiram em avaliar o ambiente em que estes trabalham, considerando não somente a parte física da Biblioteca, mas também todos os serviços voltados para aspectos ergonômicos.

Iniciou-se questionando se a Instituição possui Programa de Qualidade de Vida para os funcionários.

Quatro afirmaram não existirem Programas de Qualidade de Vida. E dois funcionários responderam que não possuem conhecimento. È interessante que fosse implantado algum tipo de atividade, pois, de acordo com pesquisas realizadas pelo British Journal of Sports Medicine, funcionários que praticam atividades físicas melhoram sua Qualidade de Vida, produzem melhor e ficam menos doentes. (VAN, et al. 2005 apud SOUZA; CERSOSIMO; VIEBIG, 2008). Sobre o Comitê Interno de Prevenção de Acidentes (CIPA), três funcionários responderam que a empresa não possui e três responderam que não sabem se a CIPA existe.

Analisando o que foi pontuado pelos respondentes, percebe-se que não existem Programas de Qualidade de Vida dentro da Instituição, e nem de prevenção de acidentes. No entanto, segundo More (1997), a CIPA é de suma importância não só na prevenção de acidentes e na segurança do trabalho, como também melhora a Qualidade de Vida dos funcionários, elaborando projetos, como Semana de Prevenção de Acidentes (SEPAT), e outros eventos que são de competência dessa comissão.

Quando questionados sobre se a Instituição oferece serviços de Ergonomia, três usuários (50\%) responderam que não oferece e três (50\%) que não conhecem esse serviço. Ao serem questionados,gostariam de conhecer melhor o 
processo de organização do trabalho: duas pessoas responderam que não lhes interessa conhecer e quatro pessoas responderam que gostariam de conhecer melhor o processo.

Analisando os dados, percebe-se que, a Instituição não possui serviços de Ergonomia. Entretanto, seria importante a aplicação de serviços de Ergonomia no ambiente, pois, segundo Falzon ; Lapeyrière (1998, apud FERREIRA, 2000), estudos de Ergonomia "[...] focalizam essencialmente o trabalho dos funcionários, a hipótese de base (frequentemente implícita) é que a melhoria das condições de trabalho dos funcionários levaria 'automaticamente' ao aprimoramento do serviço prestado e, por consequência, à satisfação do usuário". Portanto, oferecendo serviços de cunho ergonômico para os que trabalham na Instituição, possibilitaria melhor atendimento aos usuários e funcionários.

Ainda sobre essa problemática, quando perguntados - "Quais os aspectos do ambiente da Biblioteca mais prejudicam o seu trabalho?"- as respostam obtidas foram: a) aspectos ergonômicos, em relação à altura dos móveis, que não são adaptados para pessoas com estatura baixa; b) cadeiras, altura das estantes e iluminação durante o período noturno; c) desconforto nas cadeiras que ficam abaixando, sem controle prévio do usuário; d) equipamentos de informática mal instalados, mal adaptados e obsoletos; e) balcão de empréstimo ser junto com o ambiente de estudo; f) sistema de busca e indexação desatualizado; falta de qualidade das ferramentas tecnológicas utilizadas por funcionários e usuários.

Analisando as respostas dadas pelos funcionários,verificam-se novamente várias características ergonômicas incluídas nos aspectos que prejudicam o bom rendimento do trabalho. Segundo Ilda (2005), "[...] a ergonomia estuda os diversos fatores que influenciam no desempenho do sistema produtivo e procura reduzir as suas consequências nocivas sobre o trabalhador". Pode-se ainda traçar uma linha desta deficiência ergonômica com a não existência de serviços de Ergonomia apontados na questão anterior.

Na questão seguinte - "Você mudaria alguma coisa no ambiente da Biblioteca? Qual?"- as respostas vêm de encontro com os aspectos que prejudicam o trabalho. Foram elas: a) modificaria a mobília do balcão de atendimento e melhoraria a iluminação deste local; b) modificaria as cadeiras e a iluminação; c) d) modificaria os equipamentos de informática; e) modificaria o local do balcão de atendimento; f) modificaria os terminais de consulta e o sistema de busca. Mediante tais aspectos a serem observados, referentes á mobília da Biblioteca, principalmente as cadeiras e o balcão de atendimento, juntamente com a obsolescência dos equipamentos tecnológicos e a iluminação do local, características essas que apresentam certa insatisfação por parte da amostra e que deveriam ser repensadas no ambiente de trabalho. Apenas uma pessoa pontuou que não modificaria nada.

A última questão está relacionada com o que os funcionários acreditam referente a mudanças que poderiam implicar em uma melhoria no desempenho profissional. As respostas foram: a) ajudaria a ter uma melhor postura corporal e a iluminação no trabalho com computador e leitura; b) melhoraria a qualidade de vida no trabalho; c) não houve sugestões de mudanças; d) melhoraria o rendimento profissional; e) melhoraria a concentração na hora de trabalhar; f) agilizaria o processo de atendimento e garantiria a aproximação do usuário com o sistema. Novamente, apenas uma pessoa não opinou sobre mudanças.

Ao analisar as sugestões de mudanças e as possíveis melhorias sugeridas pelos funcionários, pode-se perceber que, além de um ambiente mais agradável para o trabalho, também os usuários seriam beneficiados. De acordo com Ferreira (2000, p. 5-6),o serviço de atendimento constitui [...] "diferentes lógicas que se inscrevem, por sua vez, dentro de determinadas condições físico-ambientais (espaço, luz, ruído, calor) e instrumentais (material, mobiliário, equipamentos)", se estes estiverem bem estruturados e bem organizados, tanto o usuário quanto o funcionário poderão usufruir de melhores serviços.

\subsection{Análise da percepção e diagnóstico ergonômico}

Vinculado aos aspectos físicos ambientais, até então pontuados, e que atendem aspectos da Ergonomia real da Biblioteca, no sentido de articular a percepção dos usuários, inicialmente buscou-se averiguar o que Ihes vinha em mente ao pensarem em biblioteca, para, em seguida, verificar a percepção dos mesmos sobre aspectos ergonômicos. 
Assim, o primeiro questionário foi aplicado com a finalidade de verificar a imagem que a amostra pesquisada possui de biblioteca e da Biblioteca estudada. As respostas induziram fatores ergonômicos. A primeira pergunta deste questionário foi - "Quando você pensa em biblioteca, qual a imagem lhe vem à mente?"- Por ser uma questão aberta, as respostas obtidas foram bem diversificadas. Os respondentes relataram que a primeira imagem referiu-se a estantes, livros, mesas e cadeiras, guarda-volumes, balcão de atendimento, local para estudo, para ler, local de lazer, ambiente de concentração, silêncio e local iluminado.

No gráfico, podemos observar estes dados organizados. Os pontos mais distantes do centro obtiveram maior número de respostas; os mais próximos, menor número de respostas.

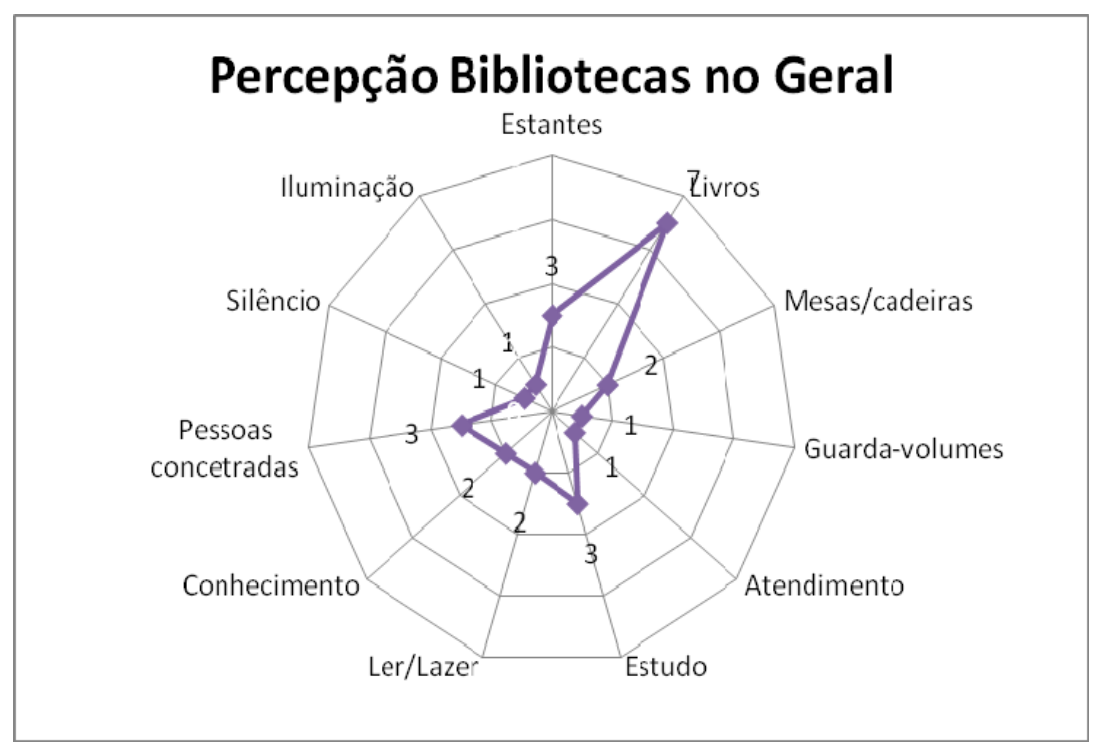

Gráfico 1 - Percepção: bibliotecas no geral

Fonte: Capri, 2011

Para traçar um paralelo entre a ideia geral de biblioteca e a imagem da Biblioteca analisada, foi perguntado: "Quando você pensa na Biblioteca desta Instituição quais as imagens que lhe vem à cabeça"- foram obtidas mais opções de respostas, sendo elas: atendentes, mesas, cadeiras, estantes, conforto, claridade, livros, guarda-volumes, salas de estudo, silêncio, estudo, concentração, organização, variedade do acervo, local amplo, banheiros, bebedouros, xadrez, usuários, periódicos e DVD's. podem-se observar estes resultados no gráfico: 


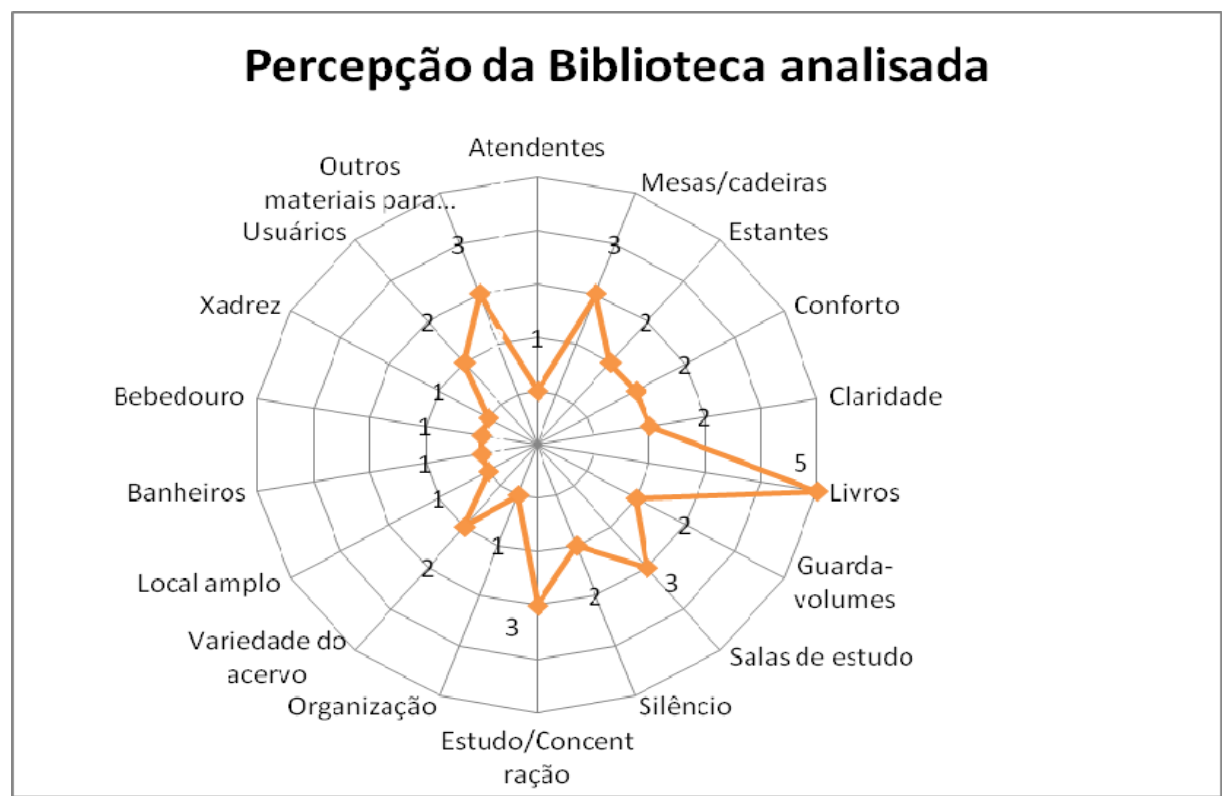

Gráfico 2 - Percepção da Biblioteca analisada

Fonte: Capri, 2011

Realizando a comparação entre os dois gráficos, percebe-se que a maioria das respostas se fazem presentes. Apenas "conhecimentos" e "ler/lazer" não aparecem em ambos. A resposta "livros" obteve maior frequência em ambos os gráficos, tendo uma pontuação de sete respostas no primeiro e cinco no segundo. Os termos estantes, livros, mesas/ cadeiras, guarda-volumes, atendentes/atendimento, estudo/concentração, silêncio e claridade/iluminação aparecem em ambos os gráficos. Infere-se então que a percepção dos usuários sobre a Biblioteca estudada não difere muito da percepção de uma biblioteca comum.

Com o intuito de reforçar o que se refere a fatores ergonômicos, entende-se Ergonomia como prática que "[...] compreende a aplicação de tecnologia da interface homem-sistema a projeto ou modificações de sistemas para aumentar a segurança, conforto e eficiência do sistema e da qualidade de vida". (MORAES; MONT'ALVÃO, 2000). E também segundo a NR 17, o mobiliário do ambiente - iluminação, ruídos, ventilação, temperatura, são identificados como fatores ergonômicos.

Tendo como parâmetro os conceitos citados, consideram-se fatores que envolvem a área da Ergonomia: silêncio (que na Ergonomia é tratado como ruído), iluminação e mesas/cadeiras, pontuados nos gráficos 1 e 2 .

No segundo gráfico, ainda são identificados termos que podem ser relacionadas à Ergonomia,ainda não abordados no primeiro, como, salas de estudo, banheiro, bebedouro, organização, conforto e local amplo.

Mediante tais dados, identifica-se que os usuários percebem a presença de aspectos Ergonômicos dentro da Biblioteca. Foi perguntado ainda: "O que você entende por ergonomia?"

As respostas obtidas foram bastante amplas, porém,não houve respostas em branco; apenas duas responderam que não tinham nenhum conhecimento sobre o tema. As características que mais apareceram nas respostas foram que a Ergonomia está relacionada ao estudo do mobiliário para melhor adaptação e conforto do trabalhador durante o expediente. Além disso, a maioria dos usuários apontaram a Ergonomia relacionada ao ambiente de trabalho; outros apresentaram a Ergonomia relacionada a normas. A relação que os usuários fizeram entre Ergonomia e ambiente de trabalho, conforto, mobiliário adequado, está diretamente aplicado ao que prescreve a Norma Regulamentadora de Ergonomia - NR 17 (2007) que "[...] visa a estabelecer parâmetros que permitam a adaptação das condições de trabalho às características psicofisiológicas dos trabalhadores, de modo a proporcionar um 
máximo de conforto, segurança e desempenho eficiente". Apenas uma pessoa citou Ergonomia em residências, fora do âmbito profissional.

Pode-se verificar que quase todos os usuários entrevistados possuem alguma noção do que poderia ser Ergonomia. Entretanto, vale ressaltar que parte desses usuários possuem conhecimentos mais específicos de Ergonomia, pois cursam Tecnólogo em Design de Interiores.Neste sentido, Pheasant (1997, apud MORAES, MONT'ALVÃO, 2000) comentam o princípio do design centrado no usuário, onde, se o objeto, ambiente ou sistema é projetado para uso humano, suas características e design devem adaptar-se às características físicas e mentais de quem vier a utilizálo. Portanto, a Ergonomia é uma ciência que tem como objetivo adaptar não só o trabalho ao homem, mas o produto ao usuário, independente do ambiente em que está inserida.

Para verificar qual a percepção que os usuários têm do ambiente, aplicou-se um questionário para observar como estes classificavam aspectos ergonômicos, como iluminação, temperatura e ruído. Foi questionado também qual o período do dia em que os usuários frequentavam a Biblioteca e quanto tempo costumavam permanecer no local, com o intuito de averiguar uma possível confiabilidade dos dados.

Referente ao turno em que frequentam a Biblioteca, oito, entre os quinze usuários, frequentavam a Biblioteca durante a tarde; dois, na parte da manhã e cinco, no período da noite. Quando questionados quanto tempo costumavam ficar dentro da Biblioteca, seis responderam até uma hora, sete responderam de uma a três horas e dois, mais de três horas. Os gráficos ilustram esses resultados.

Qual o periodo do dia costuma frequentar a biblioteca

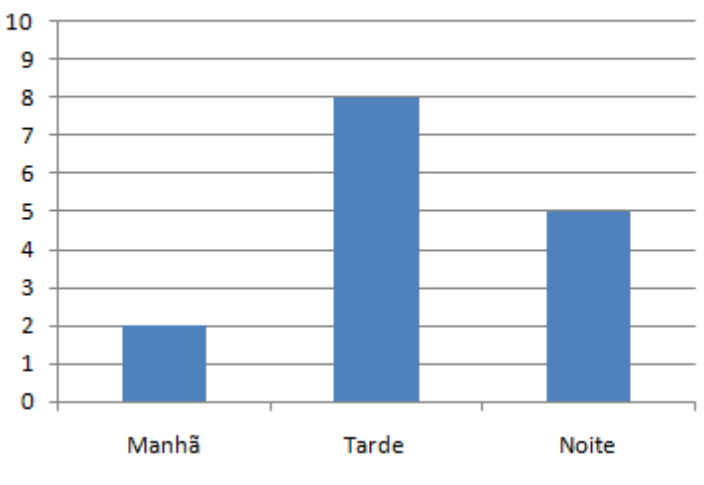

Quantas horas em média costuma ficar na biblioteca

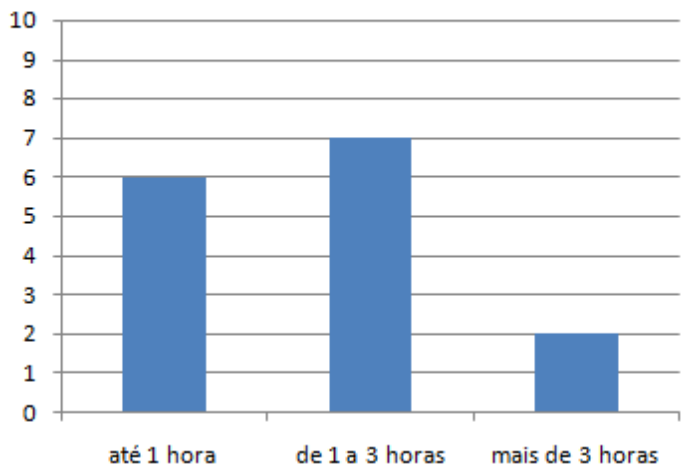

Gráfico 3 - Qual o período do dia costuma frequentar a Biblioteca/Quantas horas em média costuma ficar na Biblioteca

Fonte: Capri, 2011

Percebe-se, segundo a amostra,que a frequência à Biblioteca, em maior proporção,dá-se no período da tarde, possivelmente por ser um dos períodos mais silenciosos, pois apenas o Colégio possui aula e o movimento concentra-se no horário de intervalo.

Na sequência, foi questionado como estes usuários classificam a iluminação do local: cinco pessoas classificam como bem iluminado; oito, iluminado, e dois classificaram como mal-iluminado; ninguém classificou a Biblioteca como escura ou muito escura. Questionou-se também qual o local considerado com a iluminação mais falha e, como respostas, apontaram: salas de estudo coletivo, mesas de leitura do salão principal da Biblioteca e o setor dos periódicos.

Ainda quanto aos aspectos de análise físico-ambientais, mais especificamente, à configuração ambiental, buscouse verificar se a percepção dos usuários condiz com a realidade do ambiente da Biblioteca representada, por meio de uma medição com aparelhos específicos e com acompanhamento de um profissional da área pelo Doutorando 
em Engenharia Civil, realizada no dia 29 de outubro de 2011, no horário entre 19 horas e 15 minutos e 19 horas e 30 minutos, horário brasileiro de verão.

A medição da iluminação foi realizada com um luxímetro ${ }^{3}$, a cerca de $80 \mathrm{~cm}$ de altura do piso, quando a medição foi realizada onde não existiam mesas e sobre as mesas de estudo quando existiam, seguindo o estabelecido pela Norma NBR 5382. As medições foram feitas em 13 pontos da Biblioteca, sendo eles: P1, P2 e P3, localizados no hall de entrada; P4, P5 e P6, localizados na sala de estudos individuais; P7, na sala de estudos coletivos; P8, nas mesas do setor de periódicos. Nestes pontos, o aparelho de medição foi posicionado sobre as mesas de estudo; P9, no sofá de leitura; P10, no setor de referência; P11e P12 nas estantes. Nestes pontos, o aparelho foi posicionado a $80 \mathrm{~cm}$ do piso, que foi mantido sobre a mão da pessoa que estava realizando a medição. P13, no balcão de atendimento, onde o aparelho foi posicionado para realizar a medição sobre a parte mais baixa do balcão. Os pontos onde foram realizadas as medições são apresentados na figura que segue.

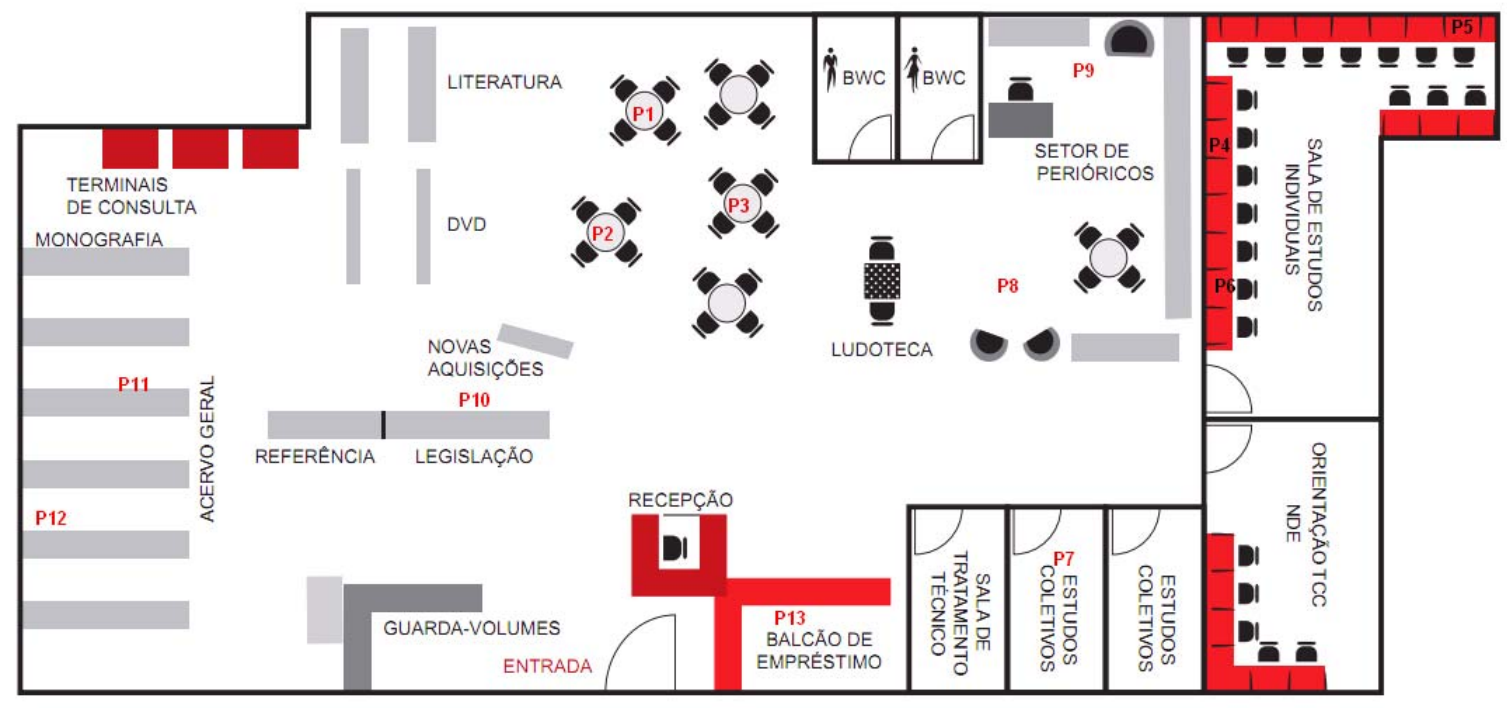

Figura 2 - Pontos de medição da biblioteca

No Quadro 1 são apresentados os resultados obtidos das medições.

Vinculado ainda aos aspectos de análise físico-ambientais, mais especificamente à configuração ambiental, buscouse verificar a percepção dos usuários condizente com a realidade do ambiente da Biblioteca, representada por meio de uma medição com aparelhos em Engenharia Civil.

Percebe-se que o ambiente não pode ser considerado silencioso, pois a maioria das pessoas assinalaram os itens "pouco barulhento e barulhento", porém, estas são opiniões individuais, o que pode não ser silencioso para uns pode ser para outros. lida (2005) afirma que as pessoas apresentam muitas diferenças individuais quanto à tolerância aos ruídos."[...] entre 70 e 90 dB dificultam a conversação e a concentração em ambiente de trabalho; o ideal é conservar o nível de ruído ambiental abaixo de 70dB", para manter um ambiente agradável. No entanto, dentro de bibliotecas, NBR10152 (níveis de ruídos para conforto acústico) recomenda que o nível de ruído esteja ente 35 e $45 \mathrm{~dB}$, o que estaria apropriado para ambientes de estudo.

Para observar se o nível de ruído da Biblioteca estava de acordo com os padrões estabelecidos pela Norma foi realizada a medição com um decibelímetro digital ${ }^{4}$ em dois pontos da Biblioteca, (P1 e P2). Assim pode-se realizar uma comparação com o que foi dito pelos alunos.Obteve-se como resultado o Quadro 2. 


\begin{tabular}{|c|c|c|}
\hline Pontos da Biblioteca & Medição (lux-unidade de medida) & $\begin{array}{c}\text { Recomendação } \\
\text { NBR5413 }- \text { Norma de } \\
\text { Iluminação }\end{array}$ \\
\hline P1 & Horário entre 19:15 a 19:30 & (lux) \\
\hline P2 & 274 & 500 \\
\hline P3 & 248 & 500 \\
\hline P4 & 136 & 500 \\
\hline P5 & 374 & 500 \\
\hline P6 & 180 & 500 \\
\hline P7 & 600 & 500 \\
\hline P8 & 260 & 500 \\
\hline P9 & 180 & 500 \\
\hline P10 & 290 & 300 \\
\hline P11 & 570 & 300 \\
\hline P12 & 334 & 500 \\
\hline
\end{tabular}

Quadro 1 - Pontos de medição de iluminação

Fonte: Capri, 2011

\begin{tabular}{|c|c|c|}
\hline Pontos da Biblioteca & Medição acústica & Recomendação \\
\hline P1 & $62 \mathrm{~dB}$ & $35-45 \mathrm{~dB}$ \\
\hline P2 & 52 a $74 \mathrm{~dB}$ & $35-45 \mathrm{~dB}$ \\
\hline
\end{tabular}

Quadro 2 - Nível de ruído da Biblioteca

Fonte: Capri, 2011

Observa-se no quadro, que em P1, onde estão localizadas as mesas de estudo e o balcão de empréstimo, o nível de ruído foi de $62 \mathrm{~dB}$, sendo que o recomendado pela Norma e de, no máximo, $45 \mathrm{~dB}$, mostrando assim que os alunos estão corretos quando apontam o ambiente como barulhento, pois, como já citado, a partir de $70 \mathrm{~dB}$, o ruído atrapalha a concentração.

Na medição realizada no P2, verificou-se uma baixa de $10 \mathrm{~dB}$, indicando o nível de ruído em $52 \mathrm{~dB}$. Neste ambiente, durante a medição, houve uma variação de $52 \mathrm{~dB}$, enquanto todos estavam em silêncio, $74 \mathrm{~dB}$; quando um aluno saiu da sala, mexeu cadeiras e bateu a porta, após o silêncio se restabelecer, o nível voltou a 52dB. Porém, ainda está acima dos valores estabelecidos pela Norma.

Referente aos barulhos que mais incomodam os usuários, são eles: conversas causadas pelos próprios usuários, som do salto dos sapatos, ruídos externos e barulho ao abrir e fechar a porta de entrada. Estes fatores estão 
diretamente ligados à primeira etapa do trabalho - a análise físico- ambiental, onde foi verificado que o piso não favorecia o silêncio, a localização do balcão de empréstimo e as mesas de estudo no mesmo ambiente prejudicavam a questão do silêncio e também por estar em cima da praça de alimentação e do local de integração dos alunos, o nível de ruídos é muito elevado.

Também considerando o local onde a Biblioteca localiza-se (sobre a praça de alimentação da Universidade), alguns odores podem ser sentidos ao longo do dia. Questionou-se então se esses odores atrapalham os estudos dos alunos. Apenas um aluno assinalou a resposta "incomodam"; o restante da amostra assinalou a alternativa "não incomodam"; as alternativas "incomodam pouco" e "incomodam muito" não foram assinaladas. Segundo Triska (2003, p. 11), "assim como nossas impressões digitais, nossa identidade odorífera é única", portanto, como quando trata-se de ruído, o que pode ser incômodo para uns, não necessariamente incomoda outros.

Ao serem questionados sobre a temperatura da biblioteca, dois usuários responderam que estão muito satisfeitos e treze que estão satisfeitos, nenhum se mostrou insatisfeito. O gráfico ilustra estes resultados

Em relação à temperatura do ambiente você está

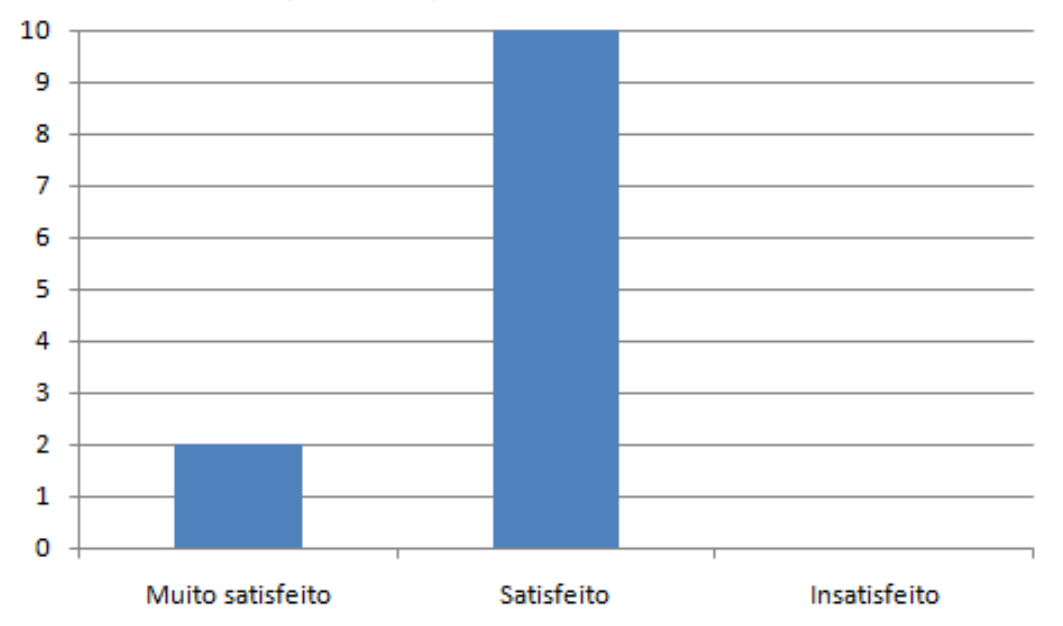

Gráfico 4 - Em relação à temperatura do ambiente

Fonte: Capri, 2011

Para verificar se a percepção dos usuários em relação à temperatura da Biblioteca vem de encontro com a temperatura real, foi realizada a medição em dois pontos: P1(onde estão as mesas e o balcão de empréstimo) e P2. O quadro apresenta o resultado obtido

\begin{tabular}{|c|c|c|}
\hline Pontos da Biblioteca & Temperatura & Recomendação \\
\hline P1 & $24,5^{\circ} \mathrm{C}$ & $20-23^{\circ} \mathrm{C}$ \\
\hline P2 & $24,6^{\circ} \mathrm{C}$ & $20-23^{\circ} \mathrm{C}$ \\
\hline
\end{tabular}

Quadro 3 - Temperatura da Biblioteca

Fonte: Capri, 2011 
A medição foi realizada no final do mês de outubro de 2011, aproximadamente um mês após a aplicação dos questionários. Percebe-se que não há grande oscilação de temperatura, pois o ambiente é climatizado, com aparelhos de ar condicionado nas salas de estudos coletivos e individual e também no salão geral. Ressalta-se que usuários possuem liberdade de solicitar aos que funcionários liguem e desliguem os aparelhos de ar condicionado, tanto nas salas de estudos, quanto no hall.

As temperaturas obtidas na medição, tanto no $\mathrm{P} 1$ quanto no $\mathrm{P} 2$, estão em torno de $24^{\circ} \mathrm{C}$. A recomendação da NR17- é que o ambiente mantenha-se entre $20^{\circ} \mathrm{C}$ e $23^{\circ} \mathrm{C}$ para que o ambiente proporcione conforto para quem está utilizando a Biblioteca.Logo, $24^{\circ} \mathrm{C}$ estaria dentro da faixa de temperatura agradável para o conforto dos usuários, principalmente se for considerado o questionário, onde ninguém está insatisfeito com a temperatura.

\section{Conclusão}

No início da pesquisa foi içada a questão acerca da importância de um trabalho inter e multidisciplinar entre os Bibliotecários responsáveis pela implantação do Programa da Percepção da Ergonomia, fatores ambientais na Biblioteca Universitária - cidade de Florianópolis/SC.

Ao realizar o diagnóstico ergonômico, os fatores analisados, como iluminação e ruído estão parcialmente de acordo com a - NR 17- normas estabelecidas pelos agentes regulamentadores. Em relação aos usuários, cinco pessoas de quinze consideram a iluminação suficiente, e seis de quinze consideram que o ruído deveria ser melhor controlado.

Referente à divisão dos ambientes dentro da Biblioteca, percebe-se que não existe uma separação entre o local do acervo, balcão de empréstimo e mesas de estudo. Esta ambientação deveria ser repensada, uma vez que o único local, onde os usuários podem obter maior aproveitamento de seus estudos resume-se às salas de estudos individuais e salas de estudos coletivos. No que se refere à ambientação da Biblioteca dentro da Universidade, esta se encontra em um local centralizado, o que facilita o acesso dos alunos.

No entanto, a questão do ruído - que constou como muito importante nesta pesquisa, é importante em relação a toda a comunidade de estudantes,usuários da Biblioteca, sendo que seis de quinze consideraram que o ruído deveria ser melhor controlado, principalmente no que concerne a horários de intervalo, o que foi confirmado ao ser realizada a medição, quando foram obtidas medidas bem acima das estabelecidas pela Norma Regulamentadora NR17-. A maioria dos usuários e funcionários considerou a temperatura adequada ao ambiente analisado, indo ao encontro do que foi verificado na medição realizada no local. Sobre a iluminação, embora a maioria da amostra de usuários tenha se mostrado satisfeita, apenas três lugares apresentaram medição superior ao indicado pela Norma.

Compreende-se que os estudos de Ergonomia podem auxiliar tanto os funcionários quanto os usuários da Biblioteca, pois estes, estando satisfeitos com o ambiente, podem produzir, quanto trabalhar de forma mais adequada às suas necessidades. Os resultados obtidos através desta pesquisa podem servir na criação de Diretrizes de Política Ergonômica para bibliotecas. 


\section{Referências}

AZEVEDO, M. de F. M. de; SANTOS, M. S. dos; OLIVEIRA, R. de. A cor no ambiente de trabalho: ergonomia da percepção. Ensaios de Ergonomia. Florianópolis, Jun, 2000. Disponível em:<http://www.eps.ufsc.br/ergon/revista/artigos/rubia.PDF>. Acesso em: 13 nov 2011.

ASSOCIAÇÃO BRASILEIRA DE NORMAS TÉCNICAS. NBR 5413: lluminância de interiores. 1992.

ASSOCIAÇÃO BRASILEIRA DE NORMAS TÉCNICAS. NBR 5382: Verificação de lluminância de Interiores. 1992.

ASSOCIAÇÃO BRASILEIRA DE NORMAS TÉCNICAS. NBR 10152: Nível de ruído para conforto acústico. 1987.

BRASIL. Ministério do Trabalho e Emprego. NR 17 - Ergonomia. Portaria MTPS n. ${ }^{\circ} 3.751$, de 23 de novembro de 1990. Disponível em: <http://portal.mte.gov.br/data/files/FF8080812BE914E6012BEFBAD7064803/nr_17.pdf>. Acesso em: 5 jun 2011.

CAPRI, Daniela. Ergonomia: um estudo de caso realizado em uma biblioteca universitária de Florianópolis. 2011.80 f. Trabalho de Conclusão de Curso. (Graduação em Biblioteconomia) - Universidade Federal de Santa Catarina, Florianópolis, 2011.

COSTA, A; ZIEGLER, A; ROLLO, F. Acústica. 1999. Disponível em: <http://campus.fortunecity.com/mcat/102/acustica.htm>. Acesso em: 14 nov 2011.

DUL, J.; WEERDMEESTER, B. Ergonomia prática. 2. ed. São Paulo: Edgard Blucher, 2004. 137 p.

FERREIRA, Mário César. Serviço de Atendimento ao Público: O que é? Como analisá-lo? Esboço de uma Abordagem TeóricoMetodológica em Ergonomia. Revista Multitemas, n. 16, mai, $2000 . \quad$ Disponível em: <http://www.ergopublic.com.br/arquivos/1252861836.07-arquivo.pdf>. Acesso em: 15 nov 2011.

GIL, Antonio Carlos.Métodos e técnicas de pesquisa social. 6. ed. São Paulo: Atlas, 2008. 200 p.

IIDA, Itiro. Ergonomia: projeto e produção. 2. ed. rev. e ampl. São Paulo: Blucher, 2005.

LEMOS, A. PAIXÃO, R. Planejamento de bibliotecas em relação ao peso. 1999. Disponível em: <http://campus.fortunecity.com/mcat/102/peso.htm>. Acesso em 15 nov 2011.

MORAES, A. de; MONT'ALVÃO, C. . Ergonomia: conceitos e aplicações. 2. ed. amp. Rio de Janeiro: 2AB, 2000. 132p.

MORE, L. F. A CIPA analisada sob a ótica da ergonomia e da organização do trabalho: proposta de criação da comissão de estudos do trabalho - CET. 1997. Dissertação (Mestrado em Engenharia de Produção), Universidade Federal de Santa Catarina, 1997. Disponível em: <http://www.eps.ufsc.br/disserta97/more/>. Acesso em: 15 nov 2011.

PEREIRA C. A. S; SILVA L. C. S.; SALES F. H. S. Análise do nível de conforto acústico na biblioteca de uma escola pública. Holos, ano 27, v. 4, set. 2011. Disponível em: <http://www2.ifrn.edu.br/ojs/index.php/HOLOS/article/viewFile/621/476>. Acesso em: 16 nov 2011.

SOUTO, G; MARX,R.; PEDREIRA, Z. Cores para bibliotecas. 1999. Disponível em: <http://campus.fortunecity.com/mcat/102/cores.htm>. Acesso em: 15 nov 2011.

SOUZA, G. M.; CERSOSIMO, P.; VIEBIG, R. F. A importância de programas de qualidade de vida em instituições corporativas. Revistadigital Efdeportes.com. Buenos Aires, ano 13 n. 124, set, 2008. Disponível em: <http://www.efdeportes.com/efd124/aimportancia-de-programas-de-qualidade-de-vida-em-instituicoes-corporativas.htm>. Acesso em: 15 nov 2011.

TRISKA, L. N. S. Prazer e bem estar no ambiente de trabalho: a importância do olfato na ergonomia. Dissertação (Mestrado em Engenharia de Produção). 2003, Universidade Federal de Santa Catarina, 2003.

VASCONCELOS, C. S. F e; VILLAROUCO, V.; SOARES, M. M. Avaliação ergonômica do ambiente construído: estudo de caso em uma biblioteca universitária. Ação ergonômica: revista brasileira de ergonomia, v.4, n.1, 2009. Disponível em: <http://www.abergo.org.br/revista/index.php/ae/article/view/69 >. Acesso em: 15 nov 2011. 


\section{Dados das autoras}

\section{Daniela Capri}

Formada em Biblioteconomia pela Universidade Federal de Santa Catarina 2011/2. Atualmente Cursa Design de Interiores na Instituição de Ensino Complexo de Ensino Superior de Santa Catarina (CESUSC). Trabalha como auxiliar de biblioteca no Complexo de Ensino Superior de Santa Catarina (CESUSC).

dccapri@gmail.com

\section{Eliana Maria dos Santos Bahia}

Graduação em Biblioteconomia e Documentação pela Universidade do Estado de Santa Catarina- UDESC (1980) Especialização em Organização e Administração de Arquivos Públicos e Empresariais pela Universidade Federal de Santa Catarina (1988) e Mestra em História do Brasil Meridional pela Universidade Federal de Santa Catarina (1994). Atualmente é professora adjunto IV do Centro de Ciência da Educação lotada no Departamento de Ciência da Informação desde 1993, Coordenadora de Estágio do Departamento de Ciência da Informação da Universidade Federal de Santa Catarina.

bahia@cin.ufsc.br

\section{Adilson Luiz Pinto}

Possui graduação em Biblioteconomia pela Pontifícia Universidade Católica de Campinas (2000), mestrado em Ciência da Informação pela Pontifícia Universidade Católica de Campinas (2004) e doutorado em Documentación pela Universidad Carlos III de Madrid (2007). Tem experiência na área de Ciência da Informação, com ênfase em Representação e Organização da Informação, atuando principalmente nos seguintes temas: Estudos Métricos da Informação (bibliometria, cienciometria, informetria e webometria) e da Documentação (Arquivometria), base de dados, recuperação de informação, fontes de informação voltados a mineração de dados para os estudos métricos e análise de redes sociais.

adilson@cin.ufsc.br

$\begin{array}{ll}\text { Recebido - Received } & : 2012-08-23 \\ \text { Aceito - Accepted } & : 2012-12-30\end{array}$

${ }^{1}$ Considerar "peso vivo" como peso das pessoas.

${ }^{2}$ Considerar "peso morto" como peso dos livros.

${ }^{3}$ Digital Lux Meter - Itld 260 - Instrutemp.

${ }^{4}$ Digital Sound Level Meter - Itdec 4000 - Instrutemp 1-Thermometer - Itht 22100 -Instrutemp;

$(\boldsymbol{\infty})$ New articles in this journal are licensed under a Creative Commons Attribution 3.0 United States License.

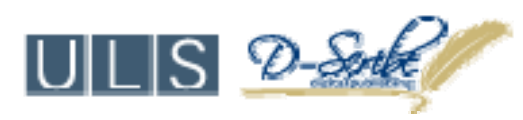

This journal is published by the University Library System of the University of Pittsburgh as part of its D-Scribe Digital Publishing Program and is cosponsored by the University of Pittsburgh Press. 